\title{
Etiology of Short Stature in Northern India
}

\author{
Manish Gutch, ${ }^{1}$ Kumar Sukriti, ${ }^{2}$ Gupta Kumar Keshav, ${ }^{3}$ Mohd Razi Syed, ${ }^{3}$ Gupta Abhinav, ${ }^{3}$ \\ Bhattacharjee Annesh, ${ }^{1}$ Ravi Mishra ${ }^{1}$
}

\author{
${ }^{1}$ Department of Medicine, King George's Medical University, Lucknow, India \\ ${ }^{2}$ Department of Radiodiagnosis, King George's Medical University, Lucknow, India \\ ${ }^{3}$ Department of Endocrinology, Lala Lajpat Rai Memorial Medical College, Meerut, India
}

\begin{abstract}
Objective. Short stature can be caused by a great variety of congenital and acquired conditions, some of which present with additional symptoms and signs. Overall, the number of patients seeking medical attention for short stature may be considered as the tip of the iceberg. The objective of this study was to determine the pattern and etiological factors of short stature in children.

Methodology. A cross-sectional study was carried out in the Department of Endocrinology at a tertiary care health center in north India from August 2012 to June 2015. Four hundred and fifty one children (280 boys and 171 girls), ranging from 4 to 18 years presenting with short stature were studied. Anthropometric measurements were plotted on Indian standard growth charts.

Results. In this study, the male to female ratio was found to be $1.6: 1$, with mean chronological age of $11.6+3.2$ years and mean bone age of $7.8+2.8$ years. The common etiologic factors in the order of frequency were constitutional delay in growth and puberty $(41.2 \%)$, familial short stature (15.9\%), type 1 diabetes mellitus $(9.9 \%)$, and hypothyroidism $(8.6 \%)$ while growth hormone deficiency $(2.4 \%)$ was a relatively uncommon cause. The most common pathological cause for proportionate short stature was type 1 diabetes and for disproportionate short stature was hypothyroidism Hypothyroidism caused the maximum retardation of bone age while the least bone age retardation was noticed in
\end{abstract} familial short stature.

Conclusion. Physiological/normal variants outnumbered the pathological causes of short stature. Endocrinological causes were found in almost one fourth of children with short stature; however, growth hormone deficiency was found in only $2.4 \%$ of the children.

Key words: constitutional growth delay, familial short stature, growth hormone deficiency, short stature

\section{INTRODUCTION}

Normal growth requires adequate nutrition along with various hormonal stimuli. Hormones important for growth and development are: growth hormone (GH), insulin-like growth factor (IGF-1), thyroid hormones, sex steroids and other growth factors ${ }^{1}$ Factors affecting growth may be due to constitutive intrinsic growth defects or any of the extrinsic factors which are required for normal growth. ${ }^{1}$

Short stature (SS) is defined as height below $3^{\text {rd }}$ percentile or less than two standard deviations (SDs) below the median height for that age and sex according to the population standard; or even if the height is within the normal percentiles but growth velocity is consistently below $25^{\text {th }}$ percentile over 6-12 months of observation. ${ }^{2,3}$ Approximately $3 \%$ of children in any population will be short, amongst which half will be physiological (familial or constitutional) and half will be pathologic. The age of onset of puberty varies in different population and it correlates more with the bone age (BA) than chronological age (CA).2,3

Children with short stature have increased rate of social aversion, anxiety and attention problem. ${ }^{4}$ Short stature may be regarded as a manifestation of many diseases rather than "a disease" itself and so, early diagnosis and treatment are imperative for the final outcome. ${ }^{5}$ Factors implicated in the pathogenesis of short stature in developing countries are different from developed countries because of the differences in race and lifestyles along with nutritional, cultural and socio-economic factors. ${ }^{6}$ In contrast to developed countries, the data addressing the frequencies of different causes of short stature in India are very limited, though there are a few studies focusing on the individual diseases. ${ }^{20}$ In this perspective, the present study was contemplated with the objective to ascertain the pattern of SS, and to find out the etiological profile of SS.
ISSN 0857-1074

Printed in the Philippines

Copyright (C) 2016 by the JAFES

Received: January 2, 2016. Accepted: April 25, 2016

Published online first May 11, 2016.

http://dx.doi.org/10.15605/jafes.031.01.05
Corresponding author: Manish Gutch, MD (Medicine), DM (Endocrinology) Assistant Professor

Department of Medicine, King George's Medical College

Lucknow, Uttar Pradesh, India, 226003

Tel. No.: 05222257242

E-mail: manish07gutch@gmail.com 


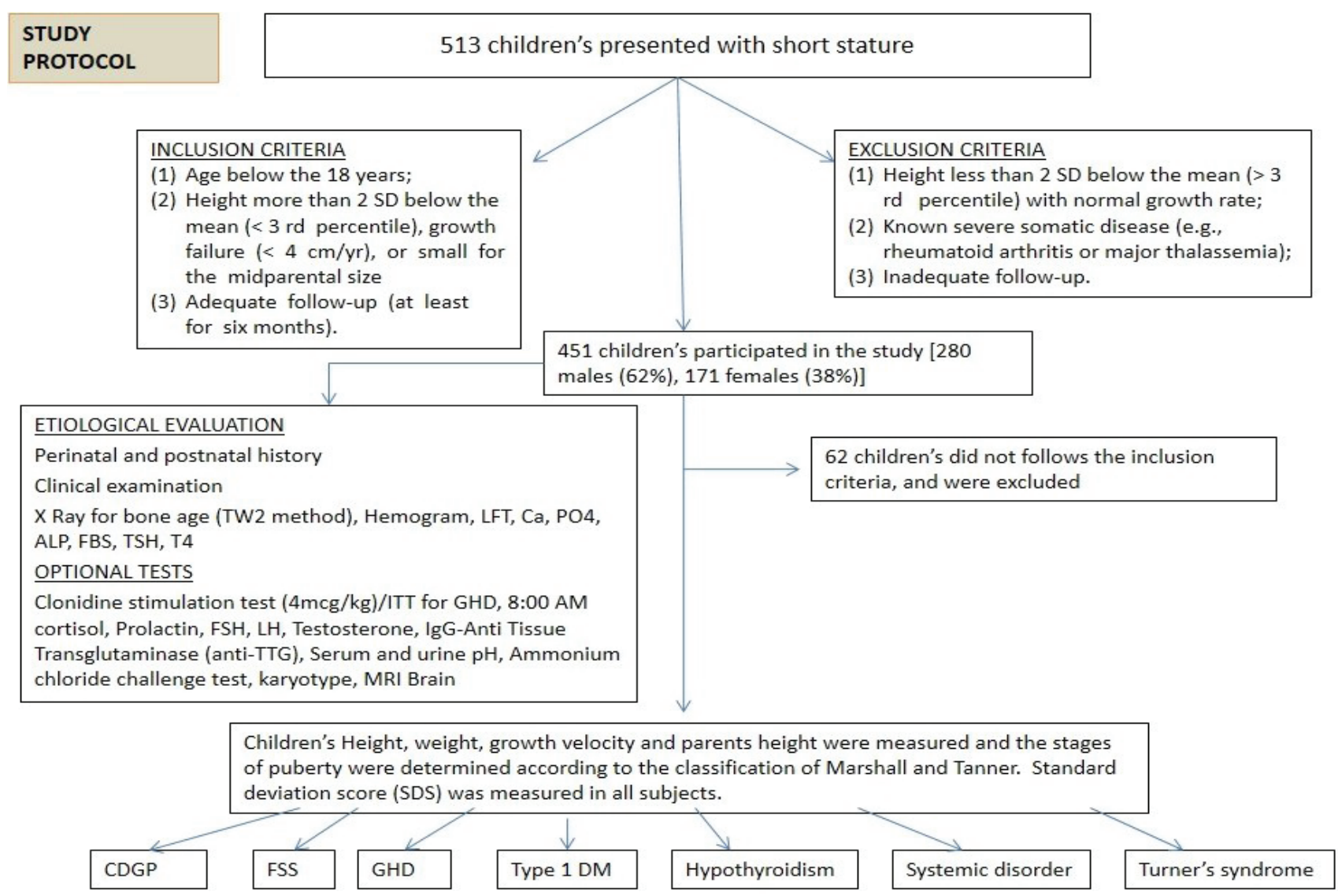

Figure 1. Summary of the study protocol and procedure for work-up and classification of subjects, $\mathrm{N}=513$ (with 451 included subjects).

\section{METHODOLOGY}

\section{Sampling and design of the study}

A cross-sectional analytic study was carried out in the Department of Endocrinology at a tertiary care health center in north India from August 2012 to June 2015. The study was approved by the institutional ethics board and all patient-identifying information remains confidential. A total of 513 children with short stature were evaluated, 62 children did not follow the inclusion criteria so the remaining 451 children participated in the study. There were 280 males (62\%) and 171 females (38\%)] were identified as having short stature, with mean chronological age of $11.68+3.2$ years. The study subjects were selected on the basis of the following inclusion criteria: (1) age below 18 years; (2) height more than 2 SD below the mean $(<3$ rd percentile), growth velocity $(<4 \mathrm{~cm} / \mathrm{yr})$, or small for the midparental size; and (3) adequate follow-up (at least for six months). The exclusion criteria were: (1) height less than 2 SD below the mean ( $>3$ rd percentile) with normal growth rate; (2) known severe somatic disease (e.g., rheumatoid arthritis or major thalassemia); and (3) inadequate followup. The study protocol is shown in Figure 1.

\section{Anthropometry and body composition}

All subjects were residents of North India referred to the endocrine clinic of a tertiary care health center. All patients were examined by two endocrinologists, including one pediatric endocrinologist. An extensive history was taken and physical examination was performed. Anthropometric measurements were taken and the puberty staging was done according to Marshall and Tanner classification. Standard deviation score (SDS) was calculated in all subjects. Patients were followed every 3-6 months interval for anthropometry assessment. Data were collected on age, sex, parental heights, and the age of puberty for each parent. Primary screening tests including routine and complete blood count, ESR, renal function test, Ca, P, Alk. $\mathrm{P}$, T4, TSH, stool exam, urinalysis, and bone age radiographs were performed in all the subjects. Bone age was determined by Tanner and Whitehouse system 2 .

Chromosomal study was performed in females with significant short stature (height more than 3 SD below the mean) and with unknown etiology, with other stigmata of Turner Syndrome. Growth aberrations were grouped as: (1) physiological/normal variants of growth and (2) pathologic short stature. The pathologic group was subdivided into proportionate and disproportionate subgroups by assessing the upper to lower segment ratio.

\section{Physiological and pathological causes of short stature}

Physiological/normal variants of short stature included constitutional delay in growth and puberty (CDGP) (i.e., 


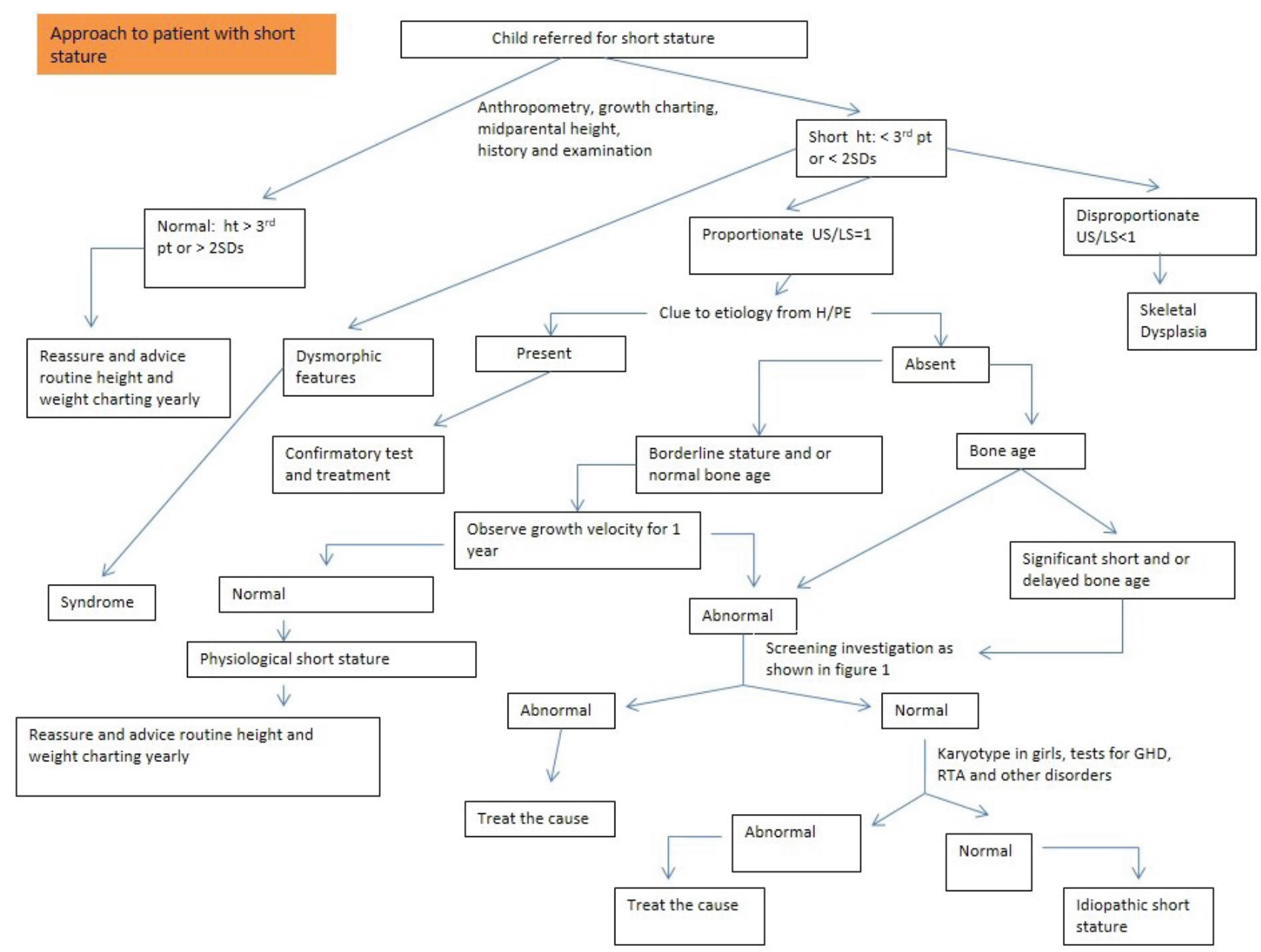

Figure 2. Approach to evaluation of short stature.

proportionate short stature with a normal growth rate, delayed skeletal maturation often with a family history of delayed pubertal development, or late adolescent growth spurt) and familial short stature (FSS) (i.e., proportionate short stature with a normal growth rate, skeletal age similar to chronologic age, absence of significant medical disorders, and short parents).

Non-endocrine systemic disorders were diagnosed by history, examination and appropriately selected laboratory tests. Primary hypothyroidism was identified by a low thyroxine level and an elevated thyrotropin level. The diagnosis of Turner syndrome was made on the basis of physical signs and confirmed by the chromosomal study.

After excluding other causes of short stature, growth hormone deficiency (GHD) was considered if a child had severely short stature (height more than 3 SD below the mean), a subnormal growth rate (a 1-year height velocity more than 1 SD below the mean) or height more than 1.5 SD below the midparental height (average of mother's and father's height), delayed bone maturation, and was confirmed by the peak growth hormone concentration less than $10 \mathrm{ng} / \mathrm{mL}$ with two provocative tests done one week apart (clonidine and insulin). ${ }^{8}$
A diagnosis of idiopathic short stature was considered in children with short stature, a subnormal growth rate, delayed bone age, no apparent medical cause for growth failure, and normal growth hormone response to provocative testing. Skeletal dysplasia was confirmed by skeletal surveys.

Approach to evaluation of short stature is shown in Figure 2.

\section{STATISTICAL ANALYSIS}

All categorical variables were expressed as frequencies and percentages and all continuous variables were expressed as mean \pm standard deviation. All $p$ values $<0.05$ were taken as significant. Statistical analysis was performed by using software SPSS version 17 .

\section{RESULTS}

A total of 513 children with short stature were evaluated, out of which 62 children did not meet the inclusion criteria, so the remaining 451 children participated in the study. Two hundred eighty males (62\%) and 171 females (38\%) were identified as having short stature, with mean chronological age of $11.68+3.2$ years, mean bone age of $7.88+2.8$ years, the minimum and maximum height measured was $96 \mathrm{~cm}$ and 


\begin{tabular}{|c|c|c|}
\hline Characteristics & Male $(n=280)$ & Female $(n=171)$ \\
\hline Chronological age (yr) & $11.65 \pm 3.2$ & $11.78 \pm 3.1$ \\
\hline Bone age (yr) & $7.86 \pm 2.8$ & $7.92 \pm 2.67$ \\
\hline Child height $(\mathrm{cm})$ & $121.65 \pm 12.24$ & $114.54 \pm 13.53$ \\
\hline Father's height $(\mathrm{cm})$ & $162.43 \pm 12.43$ & $161.87 \pm 11.78$ \\
\hline Mother's height $(\mathrm{cm})$ & $156.67 \pm 12.41$ & $156.23 \pm 11.87$ \\
\hline SDS & $-3.89 \pm 1.1$ & $-4.1 \pm 1.2$ \\
\hline
\end{tabular}

Table 2. Diagnoses of the 451 short children and adolescents, separated by gender

\begin{tabular}{|c|c|c|c|}
\hline Diagnosis & $\begin{array}{l}\text { Boys } \\
n=280\end{array}$ & $\begin{array}{c}\text { Girls } \\
\mathrm{n}=171\end{array}$ & $\begin{array}{c}\text { Total } \\
\mathrm{n}=451\end{array}$ \\
\hline Normal Variants $(\mathrm{N}=258)$ & $\mathrm{N}(\%)$ & $\mathrm{N}(\%)$ & \\
\hline CDGP & $127(45.3)$ & $59(34.5)$ & $186(41.2)$ \\
\hline FSS & $43(15.3)$ & $29(16.9)$ & $72(15.9)$ \\
\hline \multicolumn{4}{|l|}{ Pathological variants $(n=193)$} \\
\hline \multicolumn{4}{|c|}{ Proportionate causes of short stature } \\
\hline GHD & $08(2.8)$ & $03(1.7)$ & $11(2.4)$ \\
\hline Systemic diseases & $26(9.2)$ & $22(12.8)$ & $48(10.6)$ \\
\hline Panhypopituitarism & $06(2.1)$ & $02(1.1)$ & $08(1.7)$ \\
\hline Type 1 Diabetes & $31(11.07)$ & $14(8.1)$ & $45(9.9)$ \\
\hline Tumer's syndrome & ---- & $06(3.5)$ & $06(1.3)$ \\
\hline ISS & $11(3.9)$ & $01(0.5)$ & $12(2.6)$ \\
\hline \multicolumn{4}{|l|}{$\begin{array}{l}\text { Disproportionate causes of } \\
\text { short stature }\end{array}$} \\
\hline Hypothyroidism & $12(4.2)$ & $27(15.7)$ & $39(8.6)$ \\
\hline Skeletal dysplasia & $05(1.7)$ & $03(1.7)$ & $08(1.7)$ \\
\hline Rickets & $10(3.5)$ & $02(1.1)$ & $12(2.6)$ \\
\hline Pseudohypoparathyroidism & $01(0.3)$ & $03(1.7)$ & $04(0.8)$ \\
\hline Total & $280(100)$ & $171(100)$ & $451(100)$ \\
\hline
\end{tabular}

Table 3. Category wise distribution of various short stature cases

\begin{tabular}{lll}
\multicolumn{1}{c}{ Diagnosis } & $\begin{array}{c}\text { Boys } \\
\text { No. (\%) }\end{array}$ & $\begin{array}{c}\text { Girls } \\
\text { No. (\%) }\end{array}$ \\
\hline $\begin{array}{l}\text { Normal variants }(\mathrm{n}=258) \\
\text { CDGP }\end{array}$ & $127(45.3)$ & $59(34.5)$ \\
FSS & $43(15.3)$ & $29(16.9)$ \\
$\begin{array}{l}\text { Pathological variants ( } \mathrm{n}=193) \\
\text { Proportionate }\end{array}$ & \\
$\quad$ GHD & $08(2.8)$ & $03(1.7)$ \\
Systemic diseases & $26(9.2)$ & $22(12.8)$ \\
Panhypopituitarism & $06(2.1)$ & $02(1.1)$ \\
$\quad$ Tumer's syndrome & ----- & $06(3.5)$ \\
$\quad$ Type 1 Diabetes & $31(11.07)$ & $14(8.1)$ \\
$\quad$ ISS & $11(3.9)$ & $01(0.5)$ \\
Disproportionate & & \\
Hypothyroidism & $12(4.2)$ & $27(15.7)$ \\
$\quad$ Skeletal dysplasia & $05(1.7)$ & $03(1.7)$ \\
Rickets & $10(3.5)$ & $02(1.1)$ \\
\hline CDGP = Constitutional delay in growth and puberty; GHD = Growth hormone deficiency; \\
FSS = Familial short stature; ISS = Idiopathic short stature.
\end{tabular}

$141 \mathrm{~cm}$. The average height of children and their paternal and maternal heights were $119.34+12.66,162.13+12.03$, and $156.51+12.22 \mathrm{~cm}$ respectively. There was no significant difference in chronological age, bone age and parent's heights; however, a statistically significant difference was noticed in the children's height and standard deviation score between the two sexes (Table 1).

With consideration of children's age, height, growth curve, bone age and test results, the common causes of short stature were constitutional delay in growth and puberty $(41.2 \%)$, familial short stature $(15.9 \%)$, type 1 diabetes mellitus $(9.9 \%)$, primary hypothyroidism $(8.6 \%)$ and systemic disorders (including chronic liver disease, chronic renal disease, cardiac disorder, tuberculosis, nephrotic syndrome) (10.6\%) while growth hormone deficiency $(2.4 \%)$ was a relatively rare phenomenon (Table 2).

With consideration to various category wise distribution of short stature, the physiological causes for short stature (constitutional delay in growth and puberty and familial short stature) were found in $57.2 \%$ of short children and pathologic causes in $42.8 \%$ of short children. In pathologic variety of SS, majority (67.4\%) belonged to proportionate category without discernable difference in gender distribution between proportionate and disproportionate varieties. Within the proportionate variety, systemic disorders (including chronic liver disease, chronic renal disease, cardiac disorder, tuberculosis, nephrotic syndrome) and type 1 diabetes mellitus were the leading causes of short stature. However, within the disproportionate category, significantly higher numbers of girls and boys were found to have hypothyroidism (Table 3).

Furthermore, comparing the mean of SDS, bone age, chronological age, height age and growth velocity in 451 short children and adolescents, the youngest patients (3-5 years) referred to endocrine clinic for short stature had rickets and skeletal dysplasia. Late referrals (15-16.5 years) were due to systemic disorders and Turner syndrome; children with CDGP and FSS presented around the age of 13.28 years and 13.34 years respectively. On comparing the bone age of children with short stature, hypothyroidism causes the maximum bone age retardation followed by growth hormone deficiency while least bone age retardation was noticed in familial short stature (Figure 3 ).

\begin{tabular}{|c|c|c|c|c|c|}
\hline Diagnosis & $\begin{array}{l}\text { Mean of } \\
\text { chronologic age }\end{array}$ & $\begin{array}{l}\text { Mean of } \\
\text { height age }\end{array}$ & $\begin{array}{l}\text { Mean of } \\
\text { bone age }\end{array}$ & $\begin{array}{l}\text { Mean of } \\
\text { SDS }\end{array}$ & $\begin{array}{l}\text { Mean of growth } \\
\text { velocity }(\mathrm{cm} / \mathrm{yr})\end{array}$ \\
\hline CDGP & 13.28 & 10.12 & 9.5 & -2.9 & 4.6 \\
\hline FSS & 13.34 & 11.8 & 13.0 & -2.2 & 6.1 \\
\hline Hypothyroidism & 12.8 & 7.9 & 6.2 & -6.12 & 2.1 \\
\hline Type 1 Diabetes & 11.5 & 9.2 & 9.4 & -2.3 & 5.2 \\
\hline Tumer's syndrome & 16.21 & 11.2 & 10.4 & -4.6 & 3.2 \\
\hline Skeletal dysplasia & 4.1 & 2.1 & 1.8 & -5.9 & 3.7 \\
\hline Panhypopituitarism & 12.7 & 9.43 & 8.1 & -5.4 & 2.8 \\
\hline GHD & 10.34 & 7.2 & 7.0 & -6.1 & 2.4 \\
\hline Systemic diseases & 15.64 & 11.34 & 9.8 & -3.2 & 3.8 \\
\hline Rickets & 5.2 & 2.9 & 2.4 & -4.23 & 2.7 \\
\hline
\end{tabular}

CDGP = Constitutional Delay in growth and Puberty; GHD = Growth hormone deficiency; FSS = Familial short stature; ISS = Idiopathic short stature; SDS = Standard deviation score 


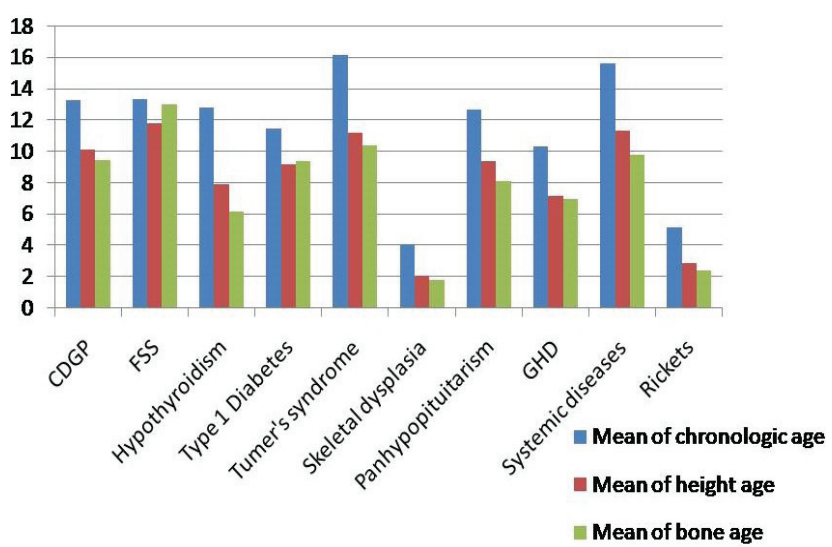

CDGP = Constitutional Delay in growth and Puberty; GHD = Growth hormone deficiency; FSS = Familial short stature; ISS = Idiopathic short stature.

Figure 3. The mean of SDS, bone age, chronological age, height age and growth velocity in 451 short children and adolescents.
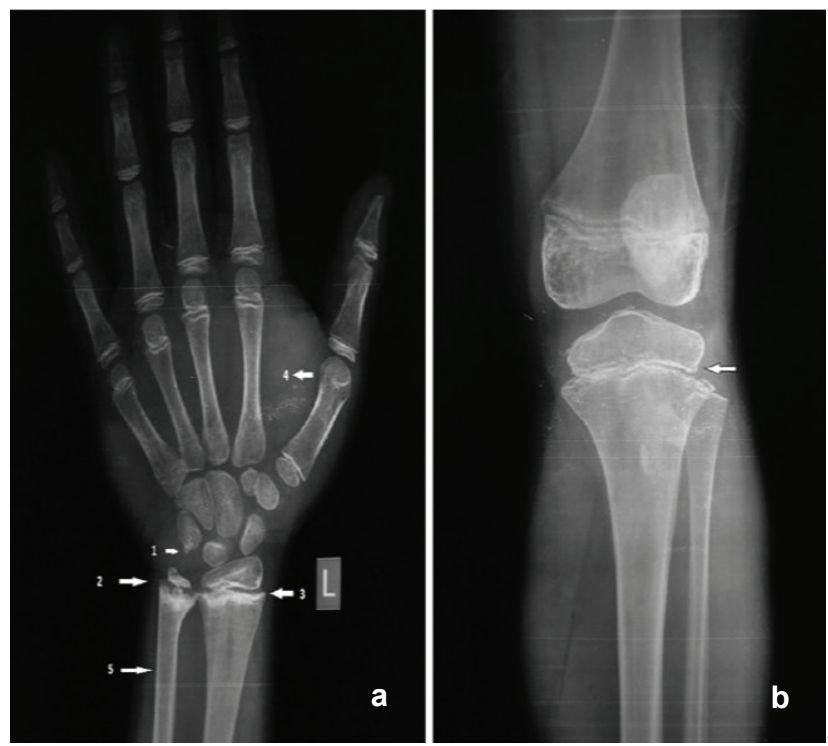

Figure 4a. $X$ ray wrist showing bone age of 10 years (chronological age 16 years) 1. Epiphysis of pisiform just appearing 2. Irregular ossification of growth plate 3 . Sclerotic band at radial metaphysis 4 . Soft tissue thickening 5. Pencil thin cortex; Figure $4 \mathrm{~b}$. $X$ ray of the knee showing heterogeneous epiphysis with irregular ossification of growth plate.

\section{DISCUSSION}

In this study, we presented characteristics and distributions of various diagnoses of short stature in children who visited a referral endocrinology clinic due to short stature over the period of 3 years. To facilitate the detection of growth disorders, growth monitoring implying regular measurements of weight and height is essential; failure to do so leads to undetected and untreated short stature in children. Short stature may be considered as the tip of the iceberg of many treatable disorders. Therefore, the early diagnosis of short stature is of paramount importance and treatment for the short stature would be effective only before epiphyseal fusion. . $^{14,20}$

The mean age of children evaluated for short stature was $11.65+3.2$ years for males and 11.78+3.1 years for females, which corresponds to data reported by Song KC et al. in their studies. There was no significant difference in chronological, bone age and parental height; however, statistically significant differences were noticed in the children's height and standard deviation scores between two sexes which also correspond to the above-mentioned study. ${ }^{17}$

The bulk of the studies worldwide had shown that constitutional delay in growth and puberty, familial short stature, and growth hormone deficiency are the most common causes of short stature..$^{9,10,11}$ In our study the most common causes found were constitutional delay in growth and puberty $(41.2 \%)$, followed by familial short stature (15.9\%), systemic diseases (10.6\%), type 1 diabetes mellitus $(9.9 \%)$ and hypothyroidism $(8.6 \%)$, while growth hormone deficiency $(2.4 \%)$ was found to be a less common cause of short stature. It is worth noting that other studies from the Indian subcontinent also show lower prevalence of growth hormone deficiency. ${ }^{12,13}$

Fortunately, most of the children with short stature have normal growth variants ${ }^{11,17}$ (i.e., constitutional delay in growth and puberty, and familial short stature), these normal variants of short stature need no medical treatment, reassurance and growth monitoring is usually sufficient. On the other hand, many serious and treatable diseases also cause short stature alone or with other stigmata of that particular disease. These pathological processes need immediate recognition and timely treatment, to ensure normal height gain. Short stature has been studied very extensively worldwide, but such work is scanty in Northern India. ${ }^{21}$

In this study, $26 \%$ of short stature children have endocrine causes (type 1 diabetes mellitus [9.9\%], hypothyroidism [8.6\%], rickets [2.6], growth hormone deficiency [2.4\%] etc) while non-endocrine causes contributed only $16.2 \%$ (systemic diseases [10.6\%], skeletal dysplasia [1.7\%], Turner syndrome [1.3\%], idiopathic short stature [2.6\%]). Studies from the different parts of the world also showed that $20-30 \%$ of short children have endocrine causes.9,10,13 Higher frequency of endocrine causes especially type 1 diabetes mellitus and hypothyroidism may be due to the referral nature of the endocrine center where the study was done. In our study, GHD contributed only $2.4 \%$, in contrast to almost one third as reported by Bhadada et al. $(7.4 \%) .{ }^{12}$ This might be due to lower prevalence of growth hormone deficiency in the Northern Indian population. Type 1 diabetes mellitus has recently gained importance as a cause of growth retardation and short stature in the Indian subcontinent and in some studies, it constitutes about $16-20 \%$ of children with short stature. ${ }^{22}$ 
However some studies found non-endocrine causes for growth failure to be more common, and the frequency of endocrine disorders were found to be less than $5 \% .{ }^{15,16}$

A disproportionate body habitus may not be immediately apparent on physical examination. Therefore, anthropometric measurements such as upper/lower segment (U/L) ratio, sitting height, and arm span must be measured when evaluating a patient with short stature. Within the proportionate variety, systemic disorders (10.6\%) and type 1 diabetes mellitus (9.9\%) were the leading causes of short stature. However, within the disproportionate category, significantly higher number of girls and boys were found to have primary hypothyroidism $(8.6 \%)$ rather than skeletal dysplasia $(1.7 \%)$. The present study very well correlated with the studies done by Moayeri $\mathrm{H}$ et al. and Song KC et al.9,17

Interestingly, besides delayed bone age, characteristic $\mathrm{x}$ rays were noted in about $75 \%$ of the hypothyroid patients (Figure 4).

In this study, there was a significant difference in GHD prevalence between genders, with boys outnumbering girls (2.6:1). Other independent reviews on growth retardation revealed that boys outnumbered girls by 2.5:1, and $2: 1^{1,10}$ which are compatible with the results obtained in this study. Thus, it appears that GHD may be more common in boys. The height SDS and growth rate were found to be significantly different between the two sexes; it may be because of male sex dominance in the community, early referral and better nutritional status of male children in the developing world.

\section{CONCLUSION}

Thus, from the clinical point of view, some points to remember: (1) The most common causes of short stature are physiological rather than pathologic (2) Determination of height velocity is the most critical factor in evaluating the growth of a child; therefore careful anthropometric measurements (height and weight) need to be made, recorded and plotted accurately on growth chart and decision-making should be based upon careful observations of growth and calculations of growth rate at an interval of not less than 6 months or preferably 12 months. (3) Treatment for the short stature would be effective only before epiphyseal fusion.

\section{Acknowledgements}

We thank the patients and their relatives for their kind participation in the research project. The contents of this publication are solely the responsibility of the authors.

\section{Ethical Consideration}

This manuscript has been duly approved by the Institutional Review Board/Ethics Committee.

\section{Statement of Authorship}

All authors have given approval to the final version submitted.

\section{Author Disclosure}

All the authors declared no conflicts of interest.

\section{Funding Source}

This research did not receive any specific grant from any funding agency in the public, commercial or not-for-profit sector.

\section{References}

1. Kamboj M. Short stature and growth hormone. Indian J Pediatr. 2005;72(2):149-57. http://dx.doi.org/10.1007/BF02760701.

2. Lifshitz F, Cervantes CD. Short stature. In: Lifshitz F, editor. Pediatric Endocrinology. 3rd ed. New York, NY: Marcel Dekker, Inc.; 1996. pp. $1-18$, revised and expanded.

3. Ghai OP, Paul VK, Bagga A. Normal growth and its disorders (eds). Essential Pediatrics, $8^{\text {th }}$ ed. New Delhi: CBS Publishers and Distributors Pvt. Ltd., 2014;1-21.

4. Zlotkin D, Varma SK. Psychological effects of short stature. Indian J Pediatr. 2006;73(1):79-80. http://dx.doi.org/10.1007/BF02758266.

5. Silventoinen K, Lahelma E, Rahkonen O. Social background, adult body-height and health. Int J Epidemiol. 1999;28(5):911-8 http://dx.doi.org/10.1093/ije/28.5.911.

6. Mohammadian S, Khoddam H. An etiologic evaluation of children with short stature in Gorgan (Northeast Iran), 2005. J Med Sci. 2007;7(7):1206-9. http://dx.doi.org/10.3923/jms.2007.1206.1209.

7. Bondy CA, and for The Turner Syndrome Consensus Study Group. Care of girls and women with Turner syndrome: A guideline of the Turner Syndrome Study Group. J Clin Endocrinol Metab. 2007; 92(1):1025. http://dx.doi.org/10.1210/jc.2006-1374\#sthash.huELc8aW.dpuf.

8. Stanley T. Diagnosis of growth hormone deficiency in childhood. Curr Opin Endocrinol Diabetes Obes. 2012;19:47-52.

9. Moayeri H, Aghighi Y. A prospective study of etiology of short stature in 426 short children and adolescents. Arch Iran Med. 2004;7:23-27.

10. Lashari SK, Korejo HB, Memon YM. To determine frequency of etiological factors in short statured patients presenting at an endocrine clinic of a tertiary care hospital. Pak J Med Sci. 2014;30(4):858-61. PMCID: PMC4121713.

11. Papadimitriou A, Douros K, Papadimitriou DT, Kleanthous K Karapanou O, Fretzayas A. Characteristics of the short children referred to an academic paediatric endocrine clinic in Greece. J Paediatr Child Health. 2012;48(3):263-7. http://dx.doi.org/10.1111/ j.1440-1754.2011.02256.x.

12. Bhadada SK, Agrawal NK, Singh SK, Agrawal JK. Etiological profile of short stature. Indian J Pediatr. 2003;70(7):545-7. http://dx.doi.org/10.1007/BF02723154.

13. Biswas, K., 2005. Short stature: Etiologically different in the developing country. Proceedings of the 7th Joint Meeting Pediatric Endocrinology, (PE'05), New Delhi, India, p. 301.

14. Frindik JP, Kemp SF, Hunold JJ. Near adult heights after growth hormone treatment in patients with idiopathic short stature or idiopathic growth hormone deficiency. J Pediatr Endocrinol Metab. 2003;16(Suppl 3):607-12. PMID: 12795361.

15. Lindsey R, Feldkamp M, Haris D, Robertson J, Rallison M. Utah growth study: Growth standards and prevalence of growth hormone deficiency. J Pediatr. 1994;125(1):29-35. http://dx.doi.org/10.1016/ S0022-3476(94)70117-2

16. Karamizadeh Z, Kashef S. An etiological profile of short stature in 11 - 14 year aged female adolescents in Shiraz. Research in Medicine [in Persian]. J Shaheed Beheshti Univ Med Sci. 1997;21:48-53.

17. Song KC, Jin SL, Kwon AR, Chae HW, Ahn JM, Kim DH, et al. Etiologies and characteristics of children with chief complaint of short stature. Ann Pediatr Endocrinol Metab 2015;20(1):34-9. http://dx.doi.org/10.6065/apem.2015.20.1.34.

18. Liu YX, Li HQ, Yang XQ, Karlberg J. Early linear growth retardation in Chongqing, China. J Paediatr Child Health. 1999;35(3):272-7. http://dx.doi.org/10.1046/j.1440-1754.1999.00378.x.

19. Gutch M, Kumar S, Razi SM, Gupta A, Kumar S, Gupta KK, et al. Prevalence of short stature in juvenile hypothyroidism and the impact of treatment on various skeletal manifestation and growth velocity in a tertiary care center. CHRISMED J Health Res. 2015;2(3):251-6. http://dx.doi.org/10.4103/2348-3334.158704.

20. Chowdhury SP, Sarkar TK, Haldar D, Taraphdar P, Naskar TK, Sarkar GN. Short stature in children: Experience from a tertiary care hospital in Kolkata, India. The Health. 2011;2(4):139-42. 
21. Kumar S, Gutch M, Razi MS, Gupta K, Arya ST. Prevalence and clinical profile of celiac disease in patients with type 1 diabetes mellitus in Western Uttar Pradesh, India. J ASEAN Fed Endocr Soc. 2015;30(2):142-6.
22. Gutch M, Kumar S, Saran S, Gupta KK, Razi SM, Philip R. Prevalence of autoimmune disorders in pediatrics type-1 diabetes mellitus in western, Uttar Pradesh, India. Int J Med Public Health. 2015;5(1):2931. http://dx.doi.org/10.4103/2230-8598.151246.

Authors are required to accomplish, sign and submit scanned copies of the JAFES Author Form consisting of: (1) the Authorship Certification that the manuscript has been read and approved by all authors, and that the requirements for authorship have been met by each author, (2) the Author Declaration that the article represents original material that is not being considered for publication or has not been published or accepted for publication elsewhere, (3) the Statement of Copyright Transferlaccepted manuscripts become the permanent property of the JAFES and are licensed with an Attribution-Share Alike-Non-Commercial Creative Commons License. Articles may be shared and adapted for non-commercial purposes as long as they are properly cited], (4) the Statement of Disclosure that there are no financial or other relationships that might lead to a conflict of interest. For Original Articles involving human participants, authors are required to submit a scanned copy of the Ethics Review Approval of their research. For manuscripts reporting data from studies involving animals, authors are required to submit a scanned copy of the Institutional Animal Care and Use Committee approval. For Case Reports or Series, and Images in Endocrinology, consent forms, are required for the publication of information about patients; otherwise, authors declared that all means have been exhausted for securing such consent. Articles and any other material published in the JAFES represent the work of the author(s) and should not be construed to reflect the opinions of the Editors or the Publisher.

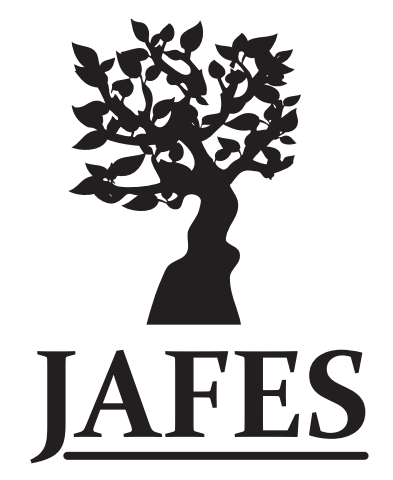

Unique, interesting, enlightening. Your case report and the JAFES. 